\title{
Diagnosis Of Endometriosis In The Light Of Prevalent Theories
}

\author{
ArfaAzhar, Rabiya Ali, Mohummad Hassan Raza Raja, Rozeena Baig, Rehana Rehman

\section{ABSTRACT:} \\ Endometriosis is a gynecological condition recognized by the existence of ectopic endometrial tissue outside the uterus. \\ It is predominantly present in females of reproductive age group and is one of the main causes of infertility. Even with a \\ predictable prevalence of $11 \%$ in females and considerable historical explanations adopted from the seventeenth century, \\ the diagnosis of endometriosis still remains doubtful. The conventional concepts on histological basis of endometriosis \\ are explained by a number of theories. Medical signs of endometriosis contain prolonged pelvic ache, dyspareunia, repeated \\ menstrual discomfort and chronic pelvic pain which can severely affect the excellence of life and health of the patient. In \\ this review we will discuss the prevalent theories for the diagnosis of endometriosis and suggestions to identify the condition \\ well in time for better control and management.
}

Key words: Endometriosis, Endometriotic lesion, angiogenesis, vascularization, vasculogenesis, endothelial progenitor cells

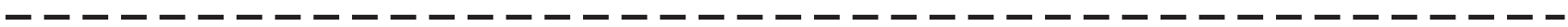

\section{INTRODUCTION:}

Endometriosis is well-defined as the existence of endometrium in uncommon or ectopic position ${ }^{1}$ Histopathologically, there is the existence of tissue or glands of the endometrial type external to the uterine cavity ${ }^{2}$. This is a gynecological condition that depends on the hormones that are observed more frequently in child bearing age women ${ }^{3}$. Frequency of endometrium is among 5\% and 10\% in premenopausal females and be able to extent up to $35 \%$ in females suffering of subfertility, as this might be main reason for infertility ${ }^{2}$. The hazardous cause of endometriosis is menarche starting at the age of 11 years as well as prolonged and heavy periods ${ }^{3}$. These two causes may raise the extra uterine environment for menstrual flow and the threat to endometriosis. The common locations for pelvic endometriosis are fallopian tubes ovaries, Douglas-fir pouch and uterine ligaments (broadly broad and uterosacral ligaments ${ }^{4}$. Endometriotic embeds are also present outside

Г- - - - - - - - - - -

Arfa Azhar

Senior Instructor Department of Biological and Biomedical sciences

Aga Khan University Hospital, Karachi

I Rabiya Ali

Senior Lecturer, Department of Physiology

I Bahria University Medical and Dental College, Karachi

Mohummad Hassan Raza Raja

I $2^{\text {nd }}$ year MBBS student

I Aga Khan University Hospital, Karachi

I Rozeena Baig

Research associate

Department of Biological \& Biomedical Sciences,

I Aga Khan University Hospital. Karachi

I

Rehana Rehman

Associate professor, Vice chair research and graduate studies

I Department of Biological and Biomedical Sciences

Aga Khan University, Karachi

IEmail: drrehana7@gmail.com

I

Received: 31-05-2019

I Accepted: 01-10-2019

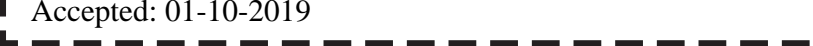

the pelvis, i.e. diaphragm, lungs, gastrointestinal tract, pericardium and abdomen ${ }^{5}$.

There are 3 main types of endometriosis present in pelvisperitoneal, ovarian, and infiltrating endometriotic disease $^{6}$. Structurally, there are 3 forms of endometriotic lesions: red lesions, white lesions and black lesions. Red are characterize by great vascularization, although white are at late stages of red lesions, assuming the development of fibrosis and inflammation. The black lesions have tissue breakdown and scarring with successive development of scar tissue ${ }^{7}$. The histological basis of endometriosis are explained by a number of theories.

\section{METHODOLOGY:}

Literature search was carried out regarding the studies conducted on Theories of Endometriosis with the key words endometriosis, endometriotic lesions, angiogenesis, vascularization, vasculogenesis endothelial progenitor cells. Through Literature searches were performed in PubMed, Medline and Google scholar for English articles. The searches included both animal and human studies (Figure 1)

Literature Review: The various theories were discussed in 43 articles for the diagnosis of endometriosis.

\section{Molecular and Cellular Theories onPathophysiologyof Endometriosis}

To date, the pathologic process of endometriosis is quiet debatable even with many years of investigations. Numerous concepts of pathology have been suggested in current years: i) implantation theory ${ }^{8}$; ii) metaplasia theory ${ }^{9}$; iii) induction theory ${ }^{10}$; iv) Epigenetic theory ${ }^{11}$; v) stem cell based theory ${ }^{12}$; vi) Perineural theory ${ }^{13}$. In recent times, it is suggested that an additional means of expressing the development and pain associated with endometriosis on the basis of inflammatory processes and initiation of nerve terminals to menstrual debris resultant retrograde and addition aluterinemenstrual flow of endometriosis ${ }^{14}$. 


\section{i) Implantation theory:}

The best frequently recognized implantation theory ${ }^{8}$ stands on hypothesis that small and early disease is recognized the consequent progression and invasion indicates towards advanced problem. These conserved endometriotic particle shave capability for attachment to the peritoneum, multiply, categorize, and attack the adjoining tissues. Additionally the distribution of endometrotic cells thru lymph nodes ${ }^{15}$ impacts over the source of disease at distant places such as cerebellar or thoracic endometriosis ${ }^{16}$.

As per requirement towards sustenance of implantation theory a number of causes take place: i) existence of backward menstruation $^{16}$; ii) occurrence of sustainable endometrial tissues to reversing refluxed menstrual flow ${ }^{16}$; and iii) binding ability of endometrial cells on peritoneum together with implantation and propagation ${ }^{17}$.

The peritoneal fluid, (PF) is filled into the peritoneal cavity, variation of fluid resulting eg. macrophage exudations, ovarian exudate, retrograde tubal fluid, transudate and reflux endometriotic material through reflux menstruation are therefore a significant component of the peritoneal surrounding ${ }^{18}$. This conversation of fluid into the pelvic cavity may explain in part the anatomical distribution of endometriotic lesions, which corresponds well to the principles of implantation biology ${ }^{19}$ and is therefore favorable to the theory of implantation. In contrast, endometriosis is only seen in a subcategory of females, despite of detail that FP comprises endometriotic tissue in equal to $59 \%$ of patients, regardless of endometriotic lesion present or menstrual cycle at any stages ${ }^{17}$. However, a persistent as well as increasing menstrual flow noticed in females having endometriosis might because of retrograde flow into the pelvis compared to healthy females having patent fallopian tubes ${ }^{20}$. Furthermore, the sealtered uterine peristalsis might be the reason for the interruption of additional basal endometrium and, hence, growing extent of stem cell-resembling cells existing in retrograde flow of menstrum ${ }^{21}$.

\section{ii) Metaplasia theory:}

The theory of metaplasia further more remains redirected in developing rest theory since poorly placed Mullerian / endometriotic tissues might be stimulated on the way to suffer metaplasia. These data are corroborated by recent evidence that emigrant primary epithelium remains or endometrium-like ectopic glands are able to create beside fetal woman reproductive system ${ }^{22}$ sustainingas likely cause for endometriotic disease. Conversely, endometrial lesions also take place at additional positions outer to the Müller canals $^{23}$.

\section{iii) Induction theory:}

The induction theory associates the theories of implantation and metaplasia and hypothesizes that unidentified materials released from the degenerating endometrium will induce the undifferentiated mesenchyme to form a tissue similar to that of the endometrium ${ }^{10}$. In summing-up, the overhead concepts emphasis over the occurrence of endometrial lesions however remain unsatisfactory to describe the happening of severe endometriosis. The progressive development of short-term disease to initial endometrial lesions and severe types approaching benign cancers could remain elucidated by cellular alterations initiating after genetic or epigenetic modifications besides is treated into the theory of endometriotic lesion(EDT) ${ }^{11}$.

\section{iv) Epigenetic theory:}

In Support of the epigenetic concept, it is found that cystic ovarian endometriosis is of clonal origin ${ }^{11}$ then certain endometrial particles are disturbing in vitro, related with loss of epithelial -cadherin appearance), a process commonly detected in cancer biology ${ }^{24}$. Furthermore, there is a combined proposal of tendency of germ line to endometriosis. Family reunification of endometriosis in humans ${ }^{25}$ and rhesus monkeys moreover to the increased prevalence between blood relatives of females having all diseases, associated to the wide spread population ${ }^{26}$ has been described. In addition, the suffered non-twin sisters are similar in ageof onset for symptoms ${ }^{27}$ and show onsistency in monozygotic twins ${ }^{28}$. Furthermore, other risk factors, such as prolonged exposure of digoxins, may to oplay a part in etiology of disease ${ }^{29}$. These comments may lead to the assumption that endometriosis is probably having complicated genetic trait where several genes work together and with the surroundings to produce the phenotype of disease ${ }^{11}$. The endometrium have a tremendously regenerative power and this is not an amazing that endometrium has stem cell properties ${ }^{30}$.

\section{v) Stem cell-based theory:}

After confirmation, that endometriosis may possibly be a stem cell-based situationstops after the statement that newly isolated endometrial stromal and epithelial cells comprise a uncommon population of cells having clonogenic property fictional in colony-forming units. (CFUs) ${ }^{31}$.

The CFUs in endometriotic stromal fractions are analogous with mesenchymal stem cells (MSCs) with respect to their differentiation potential across several lineages ${ }^{32}$. Development of endometrial type MSC cells (eMSC) is likely through expression of PDGF-Rb and CD146 perivascular cell markers. The epithelial and stromal cells Clonogenicity of the endometrium shows non-substantial predisposition dependent on stage of the menstrual cycle, with greater than before clonogenicity at the growing stage of stromal cells, at secretory stage of epithelial cells. CFUs can similarly be identified in the non-cycling endometrium ${ }^{33}$. MSC inappropriate eretrograde in the pelvis hence a serious element in forming an initial endometriotic disease. Further significance, the menstrual blood comprises plasticity particles, i.e. the re-forming cells of the endometrium (ERC) ${ }^{34}$. ERCs be similar to MSCs by their presence, growing 
possessions and prospective for differentiation into several cell categories. But, unlike MSCs, they direct matrix metalloproteases (MMP-3 and MMP-10), angiogenic factor ANG-2 and cytokines (GM-CSF, PDGF-BB) exposed by proteome investigations ${ }^{34}$.

The morphology of menstrual blood-derive MSC (discussed as MMCs or MenSCs) for example unique like as fibroblast and similar to bone marrow-derived MSCs ${ }^{35}$.

An additional research established the comprehensive plasticity of Men $\mathrm{SCs}^{36}$.

Generally, Men SC shave advanced rate of proliferation, clonogenicity and migration than angiogenic potential in vitro and bone marrow-derived MSCs in vivo studies ${ }^{37}$. Hida et al. confirmed the power of Men SC stowards there sortation developments in Myocardial Infarction rat mode $l^{38}$. Now, Men SCs contributed in reestablishment for diminished cardiac physiology thrudistinguishing into Cardiomyocytes derived from Men SC over transplant position. Therefore, menstrual blood comprises plastic cells that provide a new basis for cell-based additional managements ${ }^{39}$. These outcomes obviously designate that back ward flow of menses be able to carry stem cell in the pelvic cavity and also there may be additional cell types using putative stem / progenitor cell properties. Investigations on blood and menstrualderived plastic cells are still in its infancy. This is likewise the objective why numerous researches describe the appearance of diver seimmuno phenotypic sketches of $\mathrm{MenSC}^{40}$. A consistent attitude to segregate and describe

Figure 1; Flow Chart of Literature Review

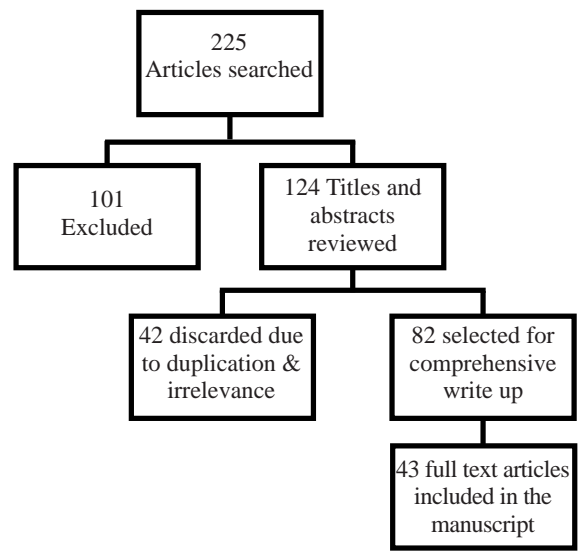

(figure:2 ) Interplay of theories of endometriosis adopted from PAB Klemm, A Starzinski - Powitz - Current Women's Health (2018)

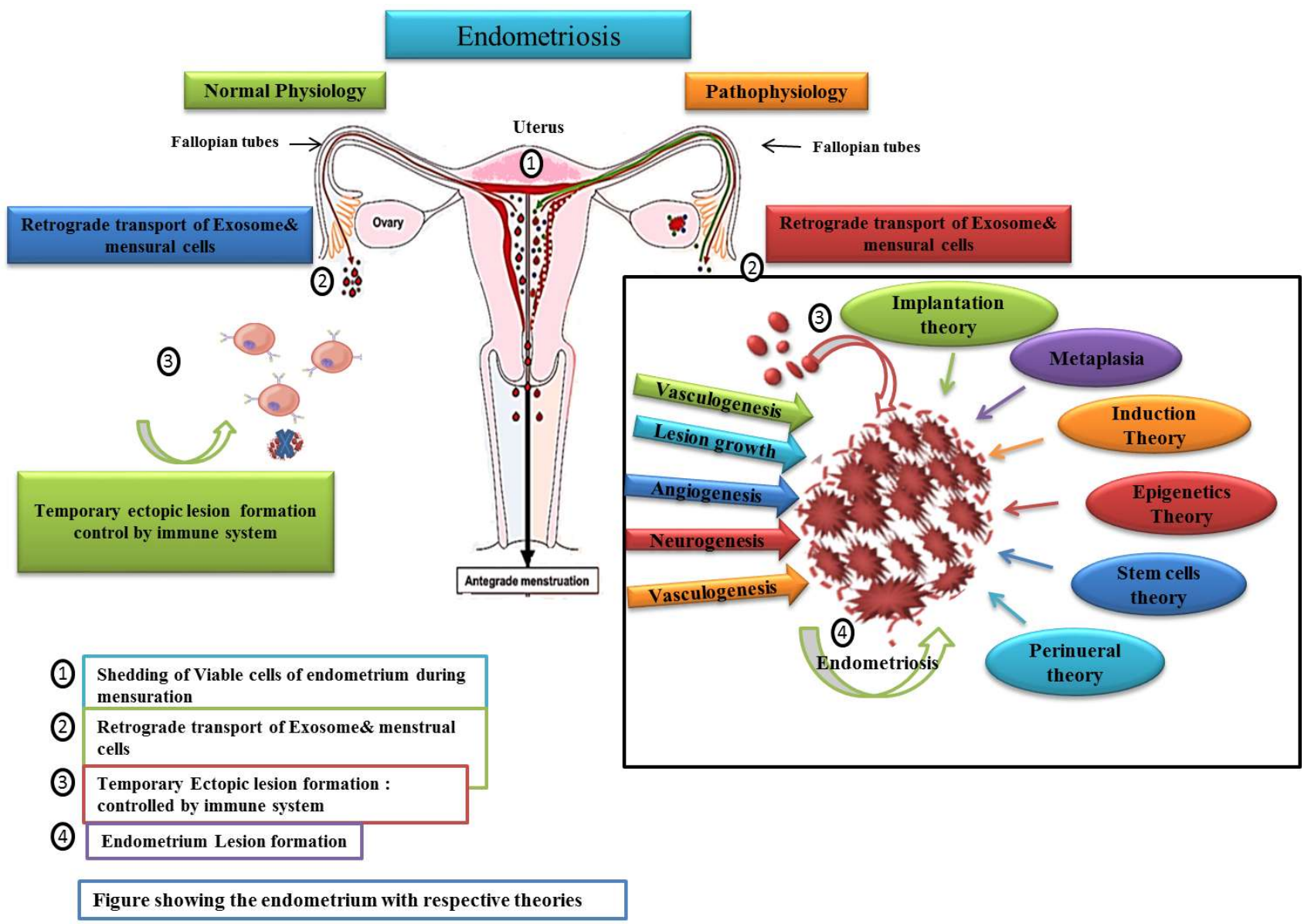


stem cells in menstrual blood is important in deciphering their title role in the pathogenesis of endometriosiss ${ }^{41}$.

\section{vi) Perineural theory:}

It was suggested the perineural extent of endometriotic lesion with in inferior hypo gastric plexus, established concept of extent of endometriosis into nerve tissues in pelvic cavity ${ }^{13}$. Meanwhile, further studies are demonstrated participation of nerves arising after lumbosacral plexus, as well as sciatic and obturator nerves ${ }^{42}$. Newly revealed biological concepts of general importance (e.g. miRNAs, stem cell-based) are also significant to the pathogenesis of endometriosis ${ }^{43}$. One challenge in endometriosis research will be to evaluate non-steroidal signaling pathways as targets for new therapeutics for the treatment of endometriosis. This may be an opportunity to substitute E2 depletion therapies to reduce undesirable effects.

\section{CONCLUSION:}

The molecular features of endometriosis include a hormonedependent (estrogen-dependent, progesterone- opposition) and inflammatory state with an epi-genetic predisposition that is most likely driven by cells with plasticity.

\section{REFERENCE:}

1. Alimi Y, Iwanaga J, Loukas M, Tubbs RS. The Clinical Anatomy of Endometriosis: A Review. Cureus. 2018;10(9): e3361-e.

2. Macer ML, Taylor HS. Endometriosis and infertility: a review of the pathogenesis and treatment of endometriosis-associated infertility. Obstetrics and Gynecology Clinics. 2012;39(4):53549.

3. Prescott J, Chavarro JE, Spiegelman D, Rich-Edwards JW, Missmer SA, Farland LV, et al. A prospective cohort study of endometriosis and subsequent risk of infertility. Human Reproduction. 2016;31(7):1475-82.

4. Vercellini P, Viganò P, Somigliana E, Fedele L. Endometriosis: pathogenesis and treatment. Nature Reviews Endocrinology. 2013;10:261-75.

5. Machairiotis N, Stylianaki A, Dryllis G, Zarogoulidis P, Kouroutou P, Tsiamis N, et al. Extrapelvic endometriosis: a rare entity or an under diagnosed condition? Diagnostic Pathology. 2013;8(1):194. doi: 10.1186/1746-1596-8-194.

6. Tosti C, Pinzauti S, Santulli P, Chapron C, Petraglia F. Pathogenetic Mechanisms of Deep Infiltrating Endometriosis. Reproductive Sciences. 2015;22(9):1053-9.

7. Alimi Y, Iwanaga J, Loukas M, Tubbs RS. The Clinical Anatomy of Endometriosis: A Review. Cureus. 2018;10(9).e3361

8. Sampson JA. The development of the implantation theory for the origin of peritoneal endometriosis. American Journal of Obstetrics and Gynecology. 1940;40(4):549-57.

9. Fujii S. Secondary mullerian system and endometriosis. Am J Obstet Gynecol. 1991;165(1):219-25.

10. Levander G, Normann P. The pathogenesis of endometriosis; an experimental study. Acta obstetricia et gynecologica Scandinavica. 1955;34(4):366-98.
11. Koninckx PR, Barlow D, Kennedy S. Implantation versus infiltration: the Sampson versus the endometriotic disease theory. Gynecologic and obstetric investigation. 1999;47 DOI:10.1159/000052853.

12. Perillo A, Bonanno G, Pierelli L, Rutella S, Scambia G, Mancuso S. Stem cells in gynecology and obstetrics. Panminerva medica. 2004;46(1):49-59.

13. Roth LM. Endometriosis with Perineural Involvement. American Journal of Clinical Pathology. 1973;59(6):807-9.

14. Laux-Biehlmann A, d'Hooghe T, Zollner TM. Menstruation pulls the trigger for inflammation and pain in endometriosis. Trends in pharmacological sciences. 2015;36(5):270-6.

15. Gong Y, Tempfer CB. Regional lymphatic spread in women with pelvic endometriosis. Medical hypotheses. 2011;76(4):560-3.

16. Augoulea A, Lambrinoudaki I, Christodoulakos G. Thoracic endometriosis syndrome. Respiration; international review of thoracic diseases. 2008;75(1):113-9.

17. van der Linden PJ, de Goeij AF, Dunselman GA, van der Linden EP, Ramaekers FC, Evers JL. Expression of integrins and E-cadherin in cells from menstrual effluent, endometrium, peritoneal fluid, peritoneum, and endometriosis. Fertility and sterility. 1994;61(1):85-90.

18. Bahtiyar MO, Seli E, Oral E, Senturk LM, Zreik TG, Arici A. Follicular fluid of women with endometriosis stimulates the proliferation of endometrial stromal cells. Human reproduction (Oxford, England). 1998;13(12):3492-5.

19. Vercellini P, Aimi G, De Giorgi O, Maddalena S, Carinelli S, Crosignani PG. Is cystic ovarian endometriosis an asymmetric disease? British journal of obstetrics and gynaecology. 1998;105(9):1018-21.

20. Bulletti C, De Ziegler D et al. Characteristics of uterine contractility during menses in women with mild to moderate endometriosis. Fertility and sterility. 2002;77(6): 1156-61.

21. D'Hooghe TM, Debrock S. Evidence that endometriosis results from the dislocation of basal endometrium? Human reproduction (Oxford, England). 2003;18(5):1130; author reply -1 .

22. Bouquet de Joliniere J, Ayoubi JM, Lesec G, Validire P, Goguin A, Gianaroli L, et al. Identification of displaced endometrial glands and embryonic duct remnants in female fetal reproductive tract: possible pathogenetic role in endometriotic and pelvic neoplastic processes. Frontiers in physiology. 2012;3:444. doi: 10.3389/fphys.2012.00444

23. Signorile PG, Baldi F, Bussani R, D'Armiento M, De Falco M, Baldi A. Ectopic endometrium in human foetuses is a common event and sustains the theory of müllerianosis in the pathogenesis of endometriosis, a disease that predisposes to cancer. Journal of Experimental \& Clinical Cancer Research. 2009;28(1):49. doi: 10.1186/1756-9966-28-49

24. Gaetje R, Kotzian S, Herrmann G, Baumann R, et. al. Nonmalignant epithelial cells, potentially invasive in human endometriosis, lack the tumor suppressor molecule E-cadherin. The American journal of pathology. 1997;150(2):461-7.

25. Kennedy S, Mardon H, Barlow D. Familial endometriosis. Journal of assisted reproduction and genetics.1995;12(1):324

26. Moen MH, Magnus P. The familial risk of endometriosis. Acta obstetricia et gynecologica Scandinavica. 1993;72(7): 560-4. 
27. Kennedy S, Hadfield R, Mardon H, Barlow D. Age of onset of pain symptoms in non-twin sisters concordant for endometriosis. Human reproduction (Oxford, England). 1996;11(2):403-5.

28. Hadfield RM, Yudkin PL, Coe CL, Scheffler J, Uno H, Barlow $\mathrm{DH}$, et al. Risk factors for endometriosis in the rhesus monkey (Macaca mulatta): a case-control study. Human reproduction update. 1997;3(2):109-15.

29. Koninckx PR, Braet P, Kennedy SH, Barlow DH. Dioxin pollution and endometriosis in Belgium. Human reproduction (Oxford, England). 1994;9(6):1001-2.

30. Yang J, Huang F. Stem cell and endometriosis: new knowledge may be producing novel therapies. International journal of clinical and experimental medicine. 2014;7(11):3853-8.

31. Chan RW, Schwab KE, Gargett CE. Clonogenicity of human endometrial epithelial and stromal cells. Biology of reproduction. 2004;70(6):1738-50.

32. Schwab KE, Gargett CE. Co-expression of two perivascular cell markers isolates mesenchymal stem-like cells from human endometrium. Human Reproduction. 2007;22(11): 2903-11.

33. Schwab KE, Chan RWS, Gargett CE. Putative stem cell activity of human endometrial epithelial and stromal cells during the menstrual cycle. Fertility and sterility. 2005;84: 1124-30.

34. Meng X, Ichim TE, Zhong J, Rogers A, Yin Z, Jackson J, et al. Endometrial regenerative cells: a novel stem cell population. Journal of translational medicine. 2007;5(1):57.

35. Musina RA, Belyavski AV, Tarusova OV, Solovyova EV, Sukhikh GT. Endometrial mesenchymal stem cells isolated from the menstrual blood. Bulletin of experimental biology and medicine. 2008;145(4):539-43.

36. Patel AN, Park E, Kuzman M, Benetti F, Silva FJ, Allickson JG. Multipotent Menstrual Blood Stromal Stem Cells: Isolation, Characterization, and Differentiation. Cell Transplantation. 2008;17(3):303-11.
37. Alcayaga-Miranda F, Cuenca J, Luz-Crawford P, Aguila-Díaz C, Fernandez A, Figueroa FE, et al. Characterization of menstrual stem cells: angiogenic effect, migration and hematopoietic stem cell support in comparison with bone marrow mesenchymal stem cells. Stem cell research \& therapy. 2015;6(1):32.

38. Hida N, Nishiyama N, Miyoshi S, Kira S, Segawa K, Uyama $\mathrm{T}$, et al. Novel cardiac precursor-like cells from human menstrual blood-derived mesenchymal cells. Stem cells. 2008;26(7):1695-704.

39. Toyoda M, Cui C, Umezawa A. Myogenic transdifferentiation of menstrual blood-derived cells. Acta myologica : myopathies and cardiomyopathies : official journal of the Mediterranean Society of Myology. 2007;26(3):176-8.

40. Khoury M, Alcayaga-Miranda F, Illanes SE, Figueroa FE. The promising potential of menstrual stem cells for antenatal diagnosis and cell therapy. Frontiers in immunology. 2014;5:205.

41. Luz-Crawford P, Torres MJ, Noël D, Fernandez A, Toupet K, Alcayaga-Miranda F, Tejedor G, Jorgensen C, Illanes SE, Figueroa FE, Djouad F. The immunosuppressive signature of menstrual blood mesenchymal stem cells entails opposite effects on experimental arthritis and graft versus host diseases. Stem cells. 2016;34(2):456-69.

42. Cimsit C, Yoldemir T, Akpinar IN. Sciatic neuroendometriosis: Magnetic resonance imaging defined perineural spread of endometriosis. Journal of Obstetrics and Gynaecology Research. 2016;42(7):890-4.

43. Petra ABK, Anna S-P. Molecular and Cellular Pathogenesis of Endometriosis. Current Women's Health Reviews. 2018;14(2):106-16. 